\title{
Congestive ischemic colitis occurring after resection of left colon cancer: 4 case series
}

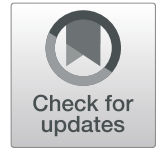

\author{
Takatsugu Fujii (DD, Shigeo Toda, Yuki Nishihara, Yusuke Maeda, Kosuke Hiramatsu, Yutaka Hanaoka, Rikiya Sato, \\ Shuichiro Matoba, Masashi Ueno and Hiroya Kuroyanagi
}

\begin{abstract}
Background: Ischemic colitis can occur after colectomy and is sometimes difficult to treat. We report 4 cases of refractory, delayed onset, regional congestive colitis occurring on the anal side of the anastomosis after laparoscopic left hemicolectomy.

Case presentation: A total of 191 patients underwent surgery for left colon cancer (transverse, descending, and sigmoid colon cancer) at our hospital from January 2012 to December 2017. During the procedures, the left colic artery (LCA) or sigmoid colic artery (SA) was dissected, the superior rectal artery (SRA) was preserved, and the inferior mesenteric vein (IMV) was dissected at the inferior margin of the pancreas. Congestive ischemic colitis due to venous return dysfunction occurred in 4 cases $(2.1 \%), 5$ to 34 months postoperatively. The patients had diarrhea and blood in the stool. On computed tomography (CT), the patients exhibited continuous intestinal edema and high-density adipose tissue from the anastomosis site to the rectum. Contrast enhancement showed dilation of the vasa recti and arteries from the inferior mesenteric artery (IMA) to the SRA. Three patients improved with long-term intestinal rest; in 1 case, the stenosis did not improve and required colorectal resection.
\end{abstract}

Conclusion: Diagnoses were easy in these cases, but treatment was prolonged and surgery was necessary in 1 case. While this condition is rare, caution is warranted as it is difficult to treat.

Keywords: Ischemic colitis, Colon cancer, Anastomosis, Colectomy

\section{Introduction}

Ischemic colitis is a condition involving mucosal inflammation and ulceration due to reduced blood flow to the colonic mucosa. The ischemia is caused by vascular factors such as arteriosclerosis, factors on the intestinal side that affect the intestine due to increased intestinal pressure from constipation or other reasons, and factors associated with congestion due to venous return dysfunction $[1,2]$.

How best to treat and preserve blood vessels during surgery for left side colon cancer is still a topic of debate. The appropriateness of lymph node dissection and how to achieve a balance with postoperative complications

\footnotetext{
*Correspondence: takatsugufujii12@gmail.com

Department of Gastrointestinal Surgery, Toranomon Hospital, 2-2-2

Toranomon, Minato-ku, Tokyo 105-8470, Japan
}

such as anastomotic leakage and ischemic colitis are also still under debate [3-5].

Here, we report our experience with 4 cases of congestive ischemic colitis that occurred after left side colon cancer surgery. We believe the colitis was caused by preserving the area from the inferior mesenteric artery (IMA) to the superior rectal artery (SRA), resecting the left colic artery (LCA) or sigmoid colic artery (SA), and dissecting the inferior mesenteric vein (IMV) both at the inferior margin of the pancreas and at the root of LCA or SA level. Several months after the procedures, the patients developed continuous ischemic colitis from the anastomosis site to the rectum with dilation of the vasa recti and arteries, as seen on computed tomography (CT).

\section{Springer Open}

(- The Author(s). 2020 Open Access This article is licensed under a Creative Commons Attribution 4.0 International License, which permits use, sharing, adaptation, distribution and reproduction in any medium or format, as long as you give appropriate credit to the original author(s) and the source, provide a link to the Creative Commons licence, and indicate if changes were made. The images or other third party material in this article are included in the article's Creative Commons licence, unless indicated otherwise in a credit line to the material. If material is not included in the article's Creative Commons licence and your intended use is not permitted by statutory regulation or exceeds the permitted use, you will need to obtain permission directly from the copyright holder. To view a copy of this licence, visit http://creativecommons.org/licenses/by/4.0/. 
We describe the pathophysiology, clinical presentations, and incidence rate of 4 cases of postoperative congestive colitis (PCC).

\section{Case presentation}

\section{Case 1: a 75-year-old woman (Table 1)}

Laparoscopic left hemicolectomy was performed for transverse colon cancer. The LCA was resected; the SA and SRA were preserved. The IMV is dissected both at the inferior margin of the pancreas and at the root of LCA level. Functional end-to-end anastomosis was performed. Nineteen months postoperatively, the patient developed diarrhea and bloody stool. CT revealed continuous edematous changes from the anastomosis site to the rectum and a high-density adipose tissue from the anastomosis site to the rectum. The patient was made nothing per os and placed under intravenous hyperalimentation management; her symptoms improved and oral intake was restarted 3 months after admission.

\section{Cases 2 and 3: 57- and 67-year-old men}

They developed colitis 6 and 34 months after surgery. The LCA was resected; the SA and SRA were preserved. The IMV is dissected both at the inferior margin of the pancreas and at the root of SA level. Case 2 colonoscopy revealed the oral side of the anastomosis was normal colon mucosa (Fig. 1a) and the anal side of anastomosis was full circumferential inflammation continued to the rectum (Fig. 1b).

They were hospitalized and were made nothing per os. Intravenous prostaglandin E1 (PGE1) was administered but showed no improvement. They clinically improved and restarted oral intake. The length of hospital stay was 55 and 52 days.

\section{Case 4: a 60-year-old man (Table 2)}

Laparoscopic left hemicolectomy was performed for descending colon cancer. The LCA and SA were resected, the SRA was preserved, and the IMV was ligated both at the inferior margin of the pancreas and at the root of SA level. The patient was discharged from the hospital on postoperative day 7 . Five months postoperatively, the patient developed diarrhea and abdominal pain, followed by blood in the stool and a fever of approximately $38^{\circ} \mathrm{C}$. A blood test showed a white blood cell (WBC) count of $18,200 / \mu \mathrm{L}$ and C-reactive protein level of $13.6 \mathrm{mg} / \mu \mathrm{L}$. CT indicated continuous intestinal edema from the anastomosis site to the rectum and signs of increased panniculitis in the surrounding area. Contrast enhancement from the IMA to the SA and SRA showed slight dilation of the straight veins and arteries in the area of intestinal edema (Fig. 2). Colonoscopy showed stenosis $15 \mathrm{~cm}$ from the anal verge, with mucosal shedding and bleeding on the oral side. The patient was made nothing per os and placed under intravenous hyperalimentation management. Intravenous PGE1 and antibiotics (cefmetazole, metronidazole) were administered but no improvement was observed. On hospital day 31, temporary ileostomy was performed. However, no improvement in the stenosis was observed on colonoscopy even after 3 months had passed. Laparoscopic low anterior resection was performed to remove the intestinal stenosis, including the anastomosis site.

Pathological examination showed complete stenosis of the colon but no necrosis, suggesting ischemia due to chronic and incomplete stenosis. There were no signs of calcification or atheroma in the arteries, though mild dilation of the arteries and veins with surrounding fibrosis was observed. No metastasis or recurrence was observed.

\section{Discussion}

Among the cases of ischemic colitis that occurred after left side colectomy, we treated 4 cases $(2.1 \%)$ in which the congestion that caused ischemic colitis occurred

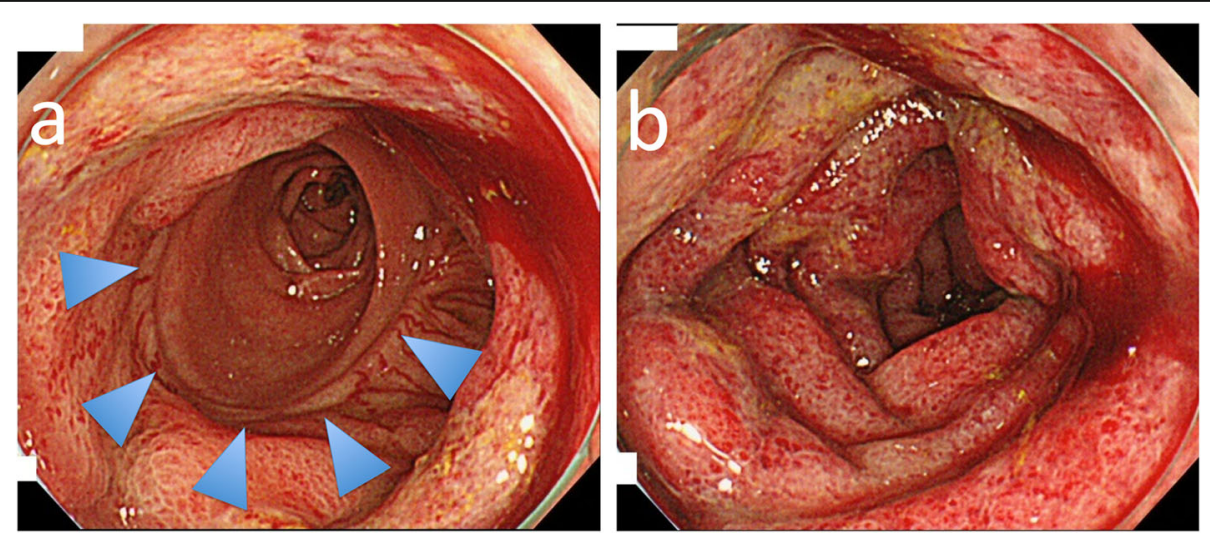

Fig. 1 a The oral side of the anastomosis was normal colon mucosa. The arrow indicates anastomosis. $\mathbf{b}$ The anal side of anastomosis was full circumferential inflammation continued to the rectum 
Table 1 Details of the operative procedures

\begin{tabular}{|c|c|c|c|c|c|c|c|c|c|}
\hline Case & $\begin{array}{l}\text { Age(Years)/ } \\
\text { Gender }\end{array}$ & $\begin{array}{l}\text { Past medical } \\
\text { history }\end{array}$ & $\begin{array}{l}\text { Ligated } \\
\text { artery }\end{array}$ & $\begin{array}{l}\text { Proximal/ Distal } \\
\text { Margin }(\mathrm{cm})\end{array}$ & $\begin{array}{l}\text { Distance between the sacral } \\
\text { promotory and anastomotic site }(\mathrm{cm})\end{array}$ & $\begin{array}{l}\text { Operative } \\
\text { time(min) }\end{array}$ & $\begin{array}{l}\text { Blood } \\
\text { loss }(\mathrm{ml})\end{array}$ & Anastomosis & $\begin{array}{l}\mathrm{f}- \\
\text { stage }\end{array}$ \\
\hline 1 & $75 / F$ & Appendicitis & LCA & $2.4 / 12.3$ & 11 & 312 & 0 & FEEA & $\|$ \\
\hline 2 & $57 / M$ & Hypertension & $\begin{array}{l}\text { LCA, } \\
\text { SA1 }\end{array}$ & $10.1 / 7.4$ & 2.5 & 268 & 0 & DST & I \\
\hline 3 & $67 / M$ & $\begin{array}{l}\text { Diabetes mellitus, } \\
\text { Hyperlipidemia }\end{array}$ & $\begin{array}{l}\text { LCA, } \\
\text { SA1,SA2 }\end{array}$ & $5 / 15.9$ & 2 & 315 & 0 & DST & I \\
\hline 4 & $60 / M$ & cholecectomy & LCA & $8.2 / 8.3$ & 7.5 & 241 & 0 & FEEA & $\|$ \\
\hline
\end{tabular}

LCA left colic artery, SA sigmoid artery, FEEA functional end-to-end anastomosis, DST double stapling technique

because the arterial branch (SRA) was preserved and the IMV was resected near the root.

Among the surgeries for colon cancer performed at our hospital from January 2012 to December 2017, left side colon cancer surgery (transverse to sigmoid colon) was performed in 753 patients. These included 191 cases of left colectomy in which the SRA was preserved and the LCA or SA was resected; the IMV was dissected both at the inferior margin of the pancreas. PCC occurred in 4 of these patients (2.1\%). PCC is defined as continuous edematous changes from the anastomosis site to the rectum, high-density adipose tissue around the mesocolon, and dilation of the vasa recti and arteries as seen on CT, as well as signs of ischemic colitis on colonoscopy.
All cases required long-term hospitalization for treatment, and in 1 case, the stenosis needed to be removed because it did not improve.

Ischemic colitis has been reported in $0.83 \%$ of cases when the IMA was treated at the root during resection of sigmoid colon or rectal cancer [3], and this condition is known to be associated with suture failure and prognosis $[4,6]$. Most cases of postoperative ischemic colitis are associated with reduced arterial blood flow. However, in a previously reported case in which the blood vessels were treated similarly to our cases, ischemic colitis on the anal side of the anastomosis that occurred 1 year postoperatively may have been PCC [7].

The arterial blood flow to the left colon comes from the IMA, which generally branches into the LCA, SA,
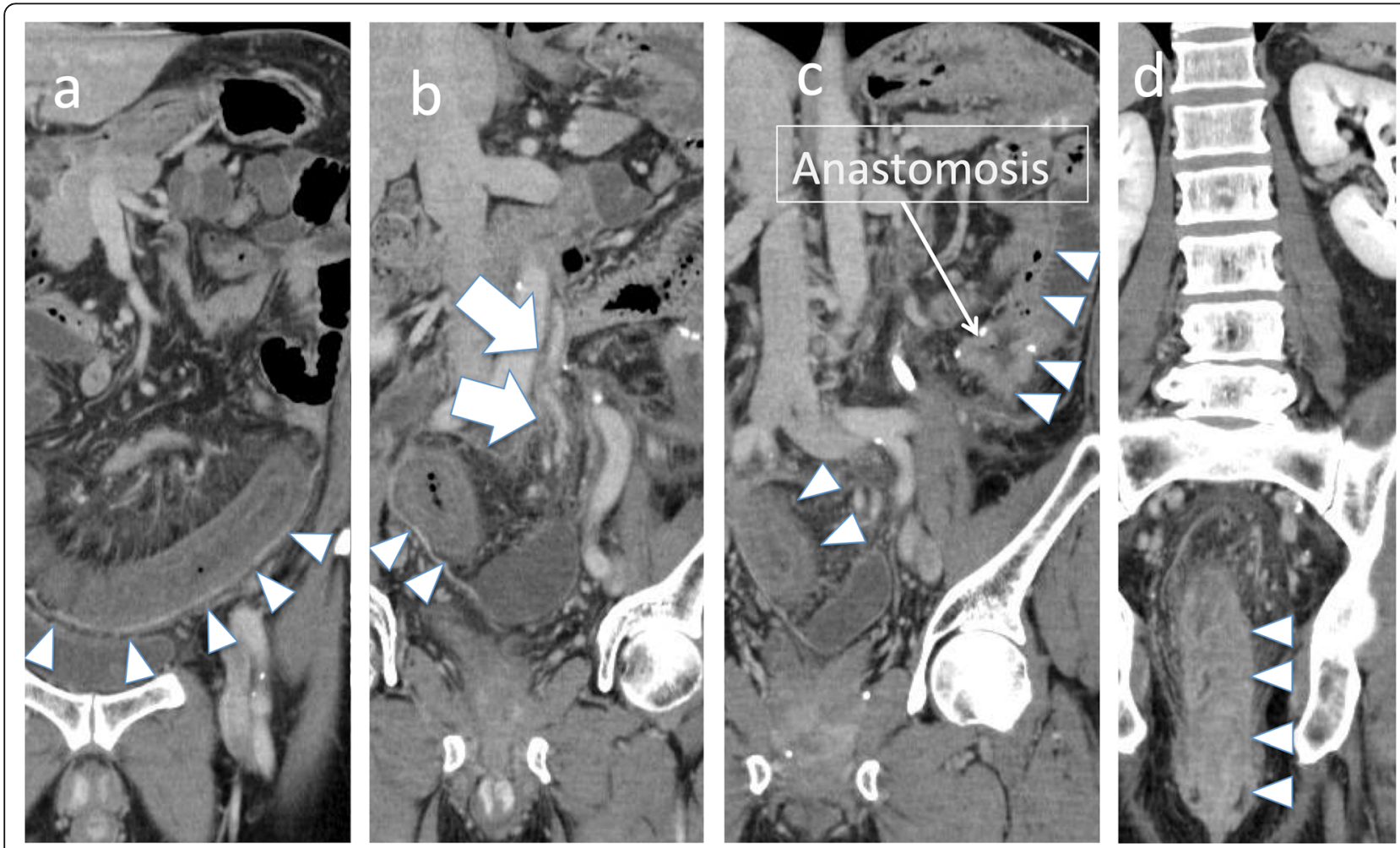

Fig $\mathbf{2}$ a There are continuous edematous changes from the anastomosis site to the rectum (triangular arrow). b Contrast enhancement shows the IMA (arrow). c, $\mathbf{d}$ The oral side of the intestines to the anastomosis seems to be normal. IMV, inferior mesenteric vein 
Table 2 Details of the treatment received by the 4 cases

\begin{tabular}{|c|c|c|c|c|c|}
\hline Case & $\begin{array}{l}\text { Time to onset from the initial } \\
\text { surgery(month) }\end{array}$ & WBC/CRP & Symptoms & $\begin{array}{l}\text { Hospital stay } \\
\text { (days) }\end{array}$ & Treatment \\
\hline 1 & $19 m$ & $8600 / 1.2$ & diarrhea,bloody stool & 157 & CMZ \\
\hline 2 & $6 m$ & $13400 / 2.2$ & diarrhea & 55 & CMZ,PGE \\
\hline 3 & $34 m$ & $12400 / 2.2$ & diarrhea & 52 & PGE \\
\hline 4 & $5 m$ & $\begin{array}{l}18200 / \\
13.6\end{array}$ & $\begin{array}{l}\text { diarrhea,abdominal pain, } \\
\text { fever }\end{array}$ & $84 ※$ & $\begin{array}{l}\mathrm{PGE}, C M Z, M T Z \text {, lleostomy,low anterior } \\
\text { resection }\end{array}$ \\
\hline
\end{tabular}

CMZ cefmetazole, PGE prostaglandin, MTZ metronidazole

*The patient underwent ileostomy and was temporarily discharged after 56 days in the hospital. He was readmitted 108 days later to undergo laparoscopic low anterior resection. He was discharged from the hospital after 28 days

and SRA (Fig. 3a). In contrast, venous blood in the left colon returns to the descending colon, sigmoid colon, and rectum via the IMV. In left colon cancer, selecting which arteries to preserve and which to remove depends on the stage and location of the tumor. When the arterial branch is preserved, treating the IMV near the root may lead to imbalances in the venous return, which can create congestion (Fig. 3b). In the present cases, contrast enhancement from the IMA to the marginal artery and vasa recti indicated that ischemia due to arterial obstruction was unlikely (Fig. 2). We certainly confirmed that the marginal artery and the vein around the anastomosis were preserved. If there had been the damage of vessel or bleeding, the congestive ischemic colitis or even anastomotic leakage could have happened earlier.
Generally, occlusion of the IMV is idiopathic, due to deficiency of protein $\mathrm{S}$ or $\mathrm{C}$, or accompanies coagulation abnormalities due to antiphospholipid antibody syndrome and presents with symptoms similar to PCC, such as mesenteric panniculitis of the colon or colitis [8-10]. Further, venous occlusion has been reported in a case of idiopathic mesenteric panniculitis [11]. In the present cases, because the IMV was resected at the inferior margin of the pancreas, we believe that venous return insufficiency caused the congestion and mesenteric panniculitis. The cause of imbalance was not clear, as mesenteric inflammation or microvascular mesenteric vein thrombosis caused venous occlusion and it may induce imbalance of blood flow.

PCC has the following 3 clinical features. First, congestion of venous return in the IMV region causes congestive

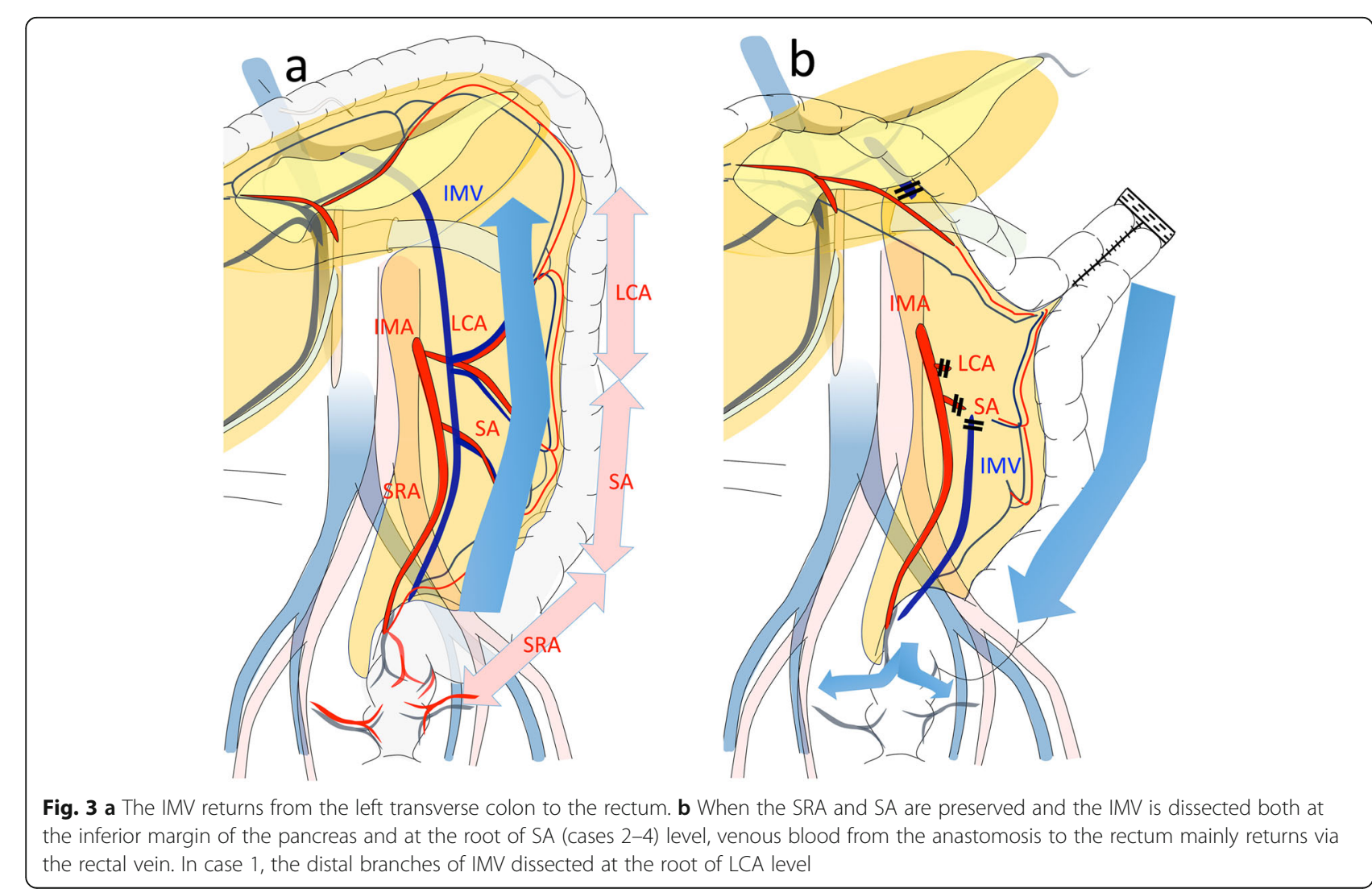


colitis continuously from the anastomosis site to near the rectum. Venous return may be reduced starting from the anastomosis site when the residual sigmoid colon (return region) is long. The distance between the sacral promontory and the anastomotic site of cases 1 and 4 was longer than cases 2 and 3 . Cases 1 and 4 needed more time to treatment (Table 1). In addition, continuous edematous changes from the anastomosis site to the rectum in CT are characteristic and make diagnosis easy.

Second, because it is venous congestion, the condition does not develop immediately after surgery; in the present cases, the condition took a median of 12.5 months (5-34 months) to appear (Table 1).

Third, all 4 cases experienced repeated watery stool from 1 week to 1 month before hospitalization. This was followed by symptoms such as abdominal pain and fever, after which diagnosis was made using CT.

Regarding treatment, resting the intestinal tract was the most effective. However, in case 4, the inflammation was severe and the stenosis on the anal side of the anastomosis did not improve even after ileostomy, making resection of the portion with colitis necessary. The inflammatory reactions did not improve even after administering antibiotics. While PEG1 has been reported to be effective for improving blood flow in postoperative ischemic colitis [12], it had no clear effects in cases 2,3 , and 4 (Table 2).

Trying to preserve as much of the IMV as possible could help prevent venous congestion, but preserving the main IMV trunk while resecting the branches is technically difficult. In transverse colon cancer, the area around the IMV is within the dissection range, which means this strategy could impact recurrence. When the IMV needs to be treated at the inferior margin of the pancreas for oncological reasons, the IMA to the SRA should not be preserved, the IMA should be dissected at the root, and anastomosis should be performed at a site with good blood flow. Alternatively, prevention may be possible by ensuring enough of the intestine on the anal side of the anastomosis is resected.

\section{Conclusion}

Our experience with 4 cases of PCC showed that while diagnosis is easy, treatment can be prolonged and there is a lack of effective treatments. Three patients improved with a conservative approach and did not experience recurrence, but 1 patient needed surgical resection due to irreversible stenosis. PCC is a rare condition and more cases need to be examined to understand its pathophysiology and how to prevent it.

\section{Abbreviations}

IMA: Inferior mesenteric artery; LCA: The left colic artery; SA: Sigmoid colic; SRA: Superior rectal artery; IMV: Inferior mesenteric vein; WBC: White blood cell; CT: Computed tomography; PCC: Postoperative congestive colitis; PGE1: Prostaglandin E1
Acknowledgements

The authors would like to thank Editage for the English language editing.

\section{Authors' contributions}

Takatsugu Fujii and Shigeo Toda contributed equally to this work; Takatsugu Fujii and Shigeo Toda designed and conducted the research and wrote the paper; Takatsugu Fujii and Shigeo Toda drafted the article, revised it critically for important intellectual content, and gave final approval for the content. All authors approved the final version of the manuscript to be submitted.

Funding

None of the authors received any funding.

\section{Availability of data and materials}

The datasets supporting the conclusions of this article are included within the article.

Ethics approval and consent to participate

Not applicable

\section{Consent for publication}

Written consent to publish was obtained from the parent of the subject, for the publication of all clinical details and images.

\section{Competing interests}

The authors declare that they have no competing interests.

Received: 31 March 2020 Accepted: 22 June 2020

Published online: 20 July 2020

\section{References}

1. Jin NC, Kim HS, Kim DH, Song YA, Kim YJ, Seo TJ, et al. A comparison of clinical characteristics between medically-treated patients and surgicallytreated patients with ischemic colitis. Clinical endoscopy. 2011;44(1):38-43.

2. Nikolic AL, Keck JO. Ischaemic colitis: uncertainty in diagnosis, pathophysiology and management. ANZ J Surg. 2018;88(4):278-83.

3. Park MG, Hur H, Min BS, Lee KY, Kim NK. Colonic ischemia following surgery for sigmoid colon and rectal cancer: a study of 10 cases and a review of the literature. Int J Color Dis. 2012;27(5):671-5.

4. Zeng J, Su G. High ligation of the inferior mesenteric artery during sigmoid colon and rectal cancer surgery increases the risk of anastomotic leakage: a meta-analysis. World J Surg Oncol. 2018;16(1):157.

5. Singh D, Luo J, Liu XT, Ma Z, Cheng H, Yu Y, et al. The long-term survival benefits of high and low ligation of inferior mesenteric artery in colorectal cancer surgery: a review and meta-analysis. Medicine. 2017;96(47):e8520.

6. Desikan SK, Singh N, Steele SR, Tran N, Quiroga E, Danaher P, et al. The incidence of ischemic colitis after repair of ruptured abdominal aortic aneurysms is decreasing in the endovascular era. Ann Vasc Surg. 2018;47: 247-52.

7. Inoue $Y$, Hashimoto T, Kitajima, et al: A case of chronic progressive ischemic colitis occurring 10 months after sigmoidectomy. Nihon Gekakei Rengo Gakkaishi (Journal of Japanese College of Surgeons). 2015;40:786-790.

8. Draganov P, Lazarchick J, Portwood G. Mesenteric vein thrombosis secondary to protein S deficiency. Am J Gastroenterol. 1999;94(12):3616-9.

9. Tsuda M, Miyazaki M, Takada T, Uda Y, Kuzuhara S. A case of protein C deficiency associated with cerebral infarction and obstruction of deep leg and inferior mesenteric veins. Jap J Psychiatr Neurol. 1993;47(4):887-92.

10. Hwang SS, Chung WC, Lee KM, Kim HJ, Paik CN, Yang JM. Ischemic colitis due to obstruction of mesenteric and splenic veins: a case report. World J Gastroenterol. 2008;14(14):2272-6.

11. Seo M, Okada M, Okina S, Ohdera K, Nakashima R, Sakisaka S. Mesenteric panniculitis of the colon with obstruction of the inferior mesenteric vein: report of a case. Dis Colon Rectum. 2001;44(6):885-9.

12. Ishihara Y, Seike M, Yokouchi I. Prostaglandin E1-effective, transient-type ischemic colitis developed after surgical resection of sigmoid colon cancer. A case report. Dig Endosc. 2003;15:240-2.

\section{Publisher's Note}

Springer Nature remains neutral with regard to jurisdictional claims in published maps and institutional affiliations. 